\title{
Correction to: Mental health in higher education students and non-students: evidence from a nationally representative panel study
}

\author{
Evangeline Tabor $^{1}\left(\mathbb{D} \cdot\right.$ Praveetha Patalay $^{1,2}$ (D) David Bann ${ }^{1}(\mathbb{C}$
}

Published online: 24 May 2021

(c) Springer-Verlag GmbH Germany, part of Springer Nature 2021

\section{Correction to: Social Psychiatry and Psychiatric Epidemiology (2021) 56:879-882 https://doi.org/10.1007/s00127-021-02032-w}

The article "Mental health in higher education students and non-students: evidence from a nationally representative panel study", written by Evangeline Tabor, Praveetha Patalay, David Bann was originally published online on 15 February 2021 with Open Access under a Creative Commons Attribution 4.0 International License.
The original article can be found online at https://doi.org/10.1007/ s00127-021-02032-w.

\section{Evangeline Tabor}

evangeline.tabor.18@ucl.ac.uk

1 Institute of Social Research, University College London, London, UK

2 Faculty of Population Health Sciences, University College London, London, UK
After publication in volume 56, issue 5, page 879-882 the author(s) decided to cancel the Open Access. Therefore, the copyright of the article has been changed on 25 May 2021 to (C) Springer-Verlag GmbH Germany, part of Springer Nature with all rights reserved.

The original article has been corrected. 